Available online at GSC Online Press Directory

GSC Biological and Pharmaceutical Sciences

e-ISSN: 2581-3250, CODEN (USA): GBPSC2

Journal homepage: https://www.gsconlinepress.com/journals/gscbps

(RESEARCH ARTICLE)

\title{
Cardioprotective effect of the aqueous extract of seeds of Datura metel (Solanaceae) on acute cardiotoxicity induced with doxorubicin in Wistar rats
}

\author{
Mbida Hacheked ${ }^{1,}{ }^{*}$, Tsala David Emery ${ }^{2}$, Aboubakar Sidiki ${ }^{1}$, Amang André Perfusion ${ }^{1}$ and Ze Minkande \\ Jacqueline ${ }^{3}$ \\ 1. Department of Biological Sciences, Faculty of Science, University of Maroua, P.O. Box 814, Maroua, Cameroon. \\ 2. Institute of Agricultural Research for Development, P.O. Box 167, Meyomessala, Cameroon. \\ 3. Faculty of Medicine and Biomedical Sciences, University of Yaoundé I, P.O. Box 1364, Yaoundé, Cameroon.
}

Publication history: Received on 28 October 2020; revised on 28 November 2020; accepted on 01 December 2020

Article DOI: https://doi.org/10.30574/gscbps.2020.13.3.0350

\begin{abstract}
The current study evaluated the cardioprotective effect of the aqueous extract of seeds of Datura metel (AESDM) on the acute cardiotoxicity induced with doxorubicin in the Wistar rats. Indeed, 30 rats have been randomized then, divided into 6 groups of 5 animals each: 3 control groups (normal, negative and positive) and 3 test groups (AESDM 100, 200 and $300 \mathrm{mg} / \mathrm{kg}$ ). These animals received orally, six consecutive days, $1 \mathrm{~mL} / 200 \mathrm{~g}$ distilled water (normal and negative control), $100 \mathrm{mg} / \mathrm{kg}$ Vitamin-E (positive control), AESDM at 100, 200 and $300 \mathrm{mg} / \mathrm{kg}$ (test groups). On the seventh day of treatment, animals in the different groups excepted the normal control received a single intraperitoneal injection of $15 \mathrm{mg} / \mathrm{kg}$ doxorubicin followed respective treatments up to the tenth day of the trial period. Serum parameters (ASAT/ALAT), biochemical markers of oxidative stress (MDA, SOD, CAT, GSH) and lipid parameters (total cholesterol, triglycerides, HDL and LDL) were evaluated. Histological sections of animal hearts were prepared. The results of this study showed that treatment with AESDM resulted in a significant decrease $(\mathrm{P}<0.001)$ in MDA, triglycerides and LDLcholesterol levels, ASAT/ALAT activity and a significant increase $(\mathrm{P}<0.001)$ in HDL-cholesterol concentration and SOD, CAT and GSH activities, compared to the negative control. Histological observation revealed that AESDM protected the heart from doxorubicin-induced damage. In conclusion, AESDM would have a cardioprotective effect that could be attributed to its antioxidant potential.
\end{abstract}

Keywords: Datura metel; Cardioprotection; Cardiotoxicity; Doxorubicin; Antioxydant

\section{Introduction}

Cardiovascular diseases (CVD) are the leading causes of death in developed and developing countries [1]. In Africa, about $30 \%$ of the population suffers from heart failure [2-3], and ischemic heart diseases are the second leading cause of death among CVD, after high blood pressure [4]. In Cameroon, ischemic heart diseases are the causes of several deaths [5]. Ischemic heart diseases are generally characterized by an imbalance in the balance between body demand and heart pump capacity [6-7], which may be due to an obstacle to blood ejection or alteration of the contractile element of the myocardium [8].

Oxidative stress is the major risk factor for ischemic heart disease [9]. It seems to be responsible for the myocytes apoptosis induction or cardiac hypertrophy [10-11]. Some drugs like doxorubicin generate reactive oxygen species (ROS) during their metabolism leading to severe cardiomyopathy [12-13]. Several cardioprotective synthetic drugs are known, such as dexrazoxane, vitamin-E, glutathione, $\beta$-blockers and many others [14]. However, these conventional

\footnotetext{
${ }^{*}$ Corresponding author: Mbida Hacheked

Department of Biological Sciences, Faculty of Science, University of Maroua, P.O. Box 814, Maroua, Cameroon.
}

Copyright $@ 2020$ Author(s) retain the copyright of this article. This article is published under the terms of the Creative Commons Attribution Liscense 4.0 
drugs, such as dexrazoxane, which are increasingly used in clinical settings, present some limitations, such as secondary cancers and serious infections development, and inhibition of the pharmacological action of certain anti-cancer drugs such as doxorubicin [15-16]. In recent decades, and despite the discovery of new synthetic chemical compounds, natural sources remain the main supplier of new drugs and chemical structures. Thus, there is a resurgence of herbal medicine, especially for products rich in polyphenols, and mainly flavonoids, which have shown interesting biological properties [17-18].

Datura metel is an American plant from Solanaceae family naturalized in many regions including Europe, Asia and Africa where it grows in wastelands and roadsides [19]. Studies conducted on this plant show that it has hypolipidemic and antihyperglycemic properties, which can be beneficial in cardiovascular disease treatment [20].

Previous work has shown its cardiotonic and antioxidant potentials on the isolated frog's heart [21]. In addition, it is mentioned in the literature that D. metel is a plant rich in alkaloids, tannins and flavonoids [22-23] which are antioxidant molecules known as protective [24-25]. The objective of this work was to assess the cardioprotective effect of the aqueous extract of seed of Datura metel (AESDM) on doxorubicin-induced cardiotoxicity in Wistar rats.

\section{Material and methods}

\subsection{Material}

\subsubsection{Plant material}

The plant material consisted of Datura metel seeds that were harvested in Koza (11 03' 15.22"N; $13^{\circ} 58^{\prime \prime} 35.09 \mathrm{E} ; 405$ $m$ alt.), Mayo-Tsanaga Division, Far North Region of Cameroon. The taxonomic identification of the plant was made by Doctor FROUMSIA MOKSIA (Botanist of the Department of Biological Sciences of the Faculty of Sciences of the University of Maroua) and authenticated at the Herbarium of the Garoua Wildlife School by comparison with existing specimen recorded under number 6408/HEFG.

\subsubsection{Animal Material}

Adult male Wistar rats aged 12 weeks and weigh between 180 and $200 \mathrm{~g}$ were obtained from the animal house Animal Health of Animal Biology Department of the Faculty of Science of the University of Ngaoundéré, Cameroon. These rats were acclimated for two weeks at the Animal Store of the Biological Sciences Laboratory of the University of Maroua, well-aerated and naturally lit (12 hours out of 24 hours) before the start of the different experiments. These animals were kept in plastic cages containing renewable wood chips every two days. The standard feed for laboratory animal (composed of corn flour (50\%), soybean flour (20\%), fish powder (15\%), calcined bone powder (4\%), palm oil (0.1\%), complex vitamin $(0.1 \%)$, cotton grain powder $(10 \%)$, cooking salt $(0.8 \%)$ just as drinking water have been given ad libitum to rats during the experimental period. Animal procedures were conducted with strict adherence to the NIH Guide for the care and use of Laboratory Animals (NIH Publication \#85-23 Rev. 1985).

\subsection{Methods}

\subsubsection{Preparation of aqueous extract of Datura metel seeds}

The seeds that had been dried in the shadow at room temperature for about two weeks, were crushed using an electric grinder (BINATONE, Model No: BLG-450). The powder obtained after grinding was then sieved using a stainless steel sieve $(16 \mathrm{~cm}$; mesh $0.8 \mathrm{~mm})$. A mass of $200 \mathrm{~g}$ of fine powder from the seeds of $D$. metel was dissolved for 1 hour in $2 \mathrm{~L}$ of distilled water heated to $70^{\circ} \mathrm{C}$. After cooling, the mixture was filtered using Whatman GF/C paper (90 mm) until a filtrate solution was obtained. The filtrate obtained was evaporated in the oven at $45 \pm 1^{\circ} \mathrm{C}$ for 48 hours until a powder was obtained and used for further experimental work.

\subsubsection{Phytochemical Screening of aqueous extract of Datura metel seeds}

Qualitative phytochemical screening was performed to determine the presence of different classes of bioactive compounds in the extract [26]. 


\subsubsection{Experiment protocol}

Cardiotoxicity induction and treatment

After acclimatization, thirty rats were randomized and divided into 6 groups of 5 animals each as follows: 3 control groups (normal, negative and positive) and 3 test groups. These animals were given orally $1 \mathrm{~mL} / 200 \mathrm{~g}$ distilled water (normal and negative control), $100 \mathrm{mg} / \mathrm{kg}$ of vitamin-E (positive control). Animals in the extract-treated group received AESDM daily at 100, 200 and $300 \mathrm{mg} / \mathrm{kg}$ (test groups) per os. On the seventh day of treatment, animals except normal control received a single intraperitoneal injection of $15 \mathrm{mg} / \mathrm{kg}$ of doxorubicin [16]. From day 8 of the trial period, animals in the positive control and those treated with different doses of AESDM received their respective treatments until day 10 of the trial period [27].

Sacrifice of animals and collection of samples

On the tenth day of the trial period, all animals were fasted for 12 hours. On the eleventh day, they were sacrificed by cervical dislocation and, then blood was immediately collected in dry tubes after rupture of the jugular vein. This blood was centrifuged at $3000 \mathrm{trs} / \mathrm{min}$ for 15 minutes using a centrifuge (UNIVERSAL $320 \mathrm{R}$ HETTICH). The serum was separated and collected for assay biochemical parameters. Subsequently, the heart of each rat was removed and divided into two parts. A portion $(0.5 \mathrm{~g}$ ) of each core was ground in a glass mortar and homogenized in $2.8 \mathrm{~mL}$ phosphate buffer. The homogenates were centrifuged at 3000 revolutions for $10 \mathrm{~min}$ at $4^{\circ} \mathrm{C}$ and the supernatant was collected, aliquoted and stored at $-6^{\circ} \mathrm{C}$ until the various biochemical parameters were analyzed. The second part of each core was rinsed in a saline solution $(0.9 \%)$, then fixed in $10 \%$ formalin for histological sections.

\section{Analysis of transaminases activities (ASAT/ALAT)}

The analysis of transaminases such as alanine-aminotransferase (ALAT) and aspartate-aminotransferase (ASAT) in serum was carried out according to the protocol described by Murray [28] using the CHRONOLAB kit. This assay was performed using a MINDRAY BC-2800 semi-automatic spectrophotometer. The apparatus was programmed and calibrated for reading according to the instructions given in the instructions for each reagent.

Evaluation of some oxidative stress parameters

Malondialdehyde (MDA) concentration was evaluated using the method described by Wilbur et al [29]; superoxide dismutase (SOD), catalase (CAT) and reduced glutathione (GSH) activities have been measured according to the methods described respectively by Misra and Fridovich [30], Sinha [31] and Ellman [32] in the homogenates of the different hearts.

\section{Evaluation of lipid parameters}

Total cholesterol rate, triglycerides were evaluated using a colorimetric enzymatic method described by Parekh et al [33], Rice [34], respectively, using the DIALAB and INMESCO kits. Lipoprotein levels (HDL and LDL) were evaluated using the method described by Burstein and Scholnick [35].

\section{Histopathological examination}

After fixation, these hearts were treated with alcohol and xylene respectively at different concentrations, impregnated in paraffin wax and then sectioned at $4 \mu \mathrm{m}$ for the preparation of white blades. The obtained white slides were stained with haematin and eosin respectively for reading under the photonic microscope (Olympus BX51) and for capturing micrographs (G40X, 100X, and $200 \mathrm{X}$ ).

\subsection{Data analysis}

Statistical analysis of the results was done using the Graph pad Prism 5.00 software. The results were presented as mean \pm SEM, for a number $n=5$ rats per batch. Following the single-channel variance analysis (ANOVA), intergroup averages were compared using the non-parametric Turkey test. Significant differences were considered at the 0.05 probability threshold.

\section{Results and discussion}

\subsection{Results}




\subsubsection{Qualitative phytochemical screening of AESDM result}

Phytochemical screening revealed the presence of alkaloids, glycosides and phenolic compounds such as flavonoids and tannins.

\subsubsection{Extract effect on the transaminase activities}

Table 1 presents the variations in transaminase activity (ASAT/ALAT) in the different groups of animals injected with doxorubicin and treated with vitamin-E and AESDM respectively. From this table, it appears that rats given an intraperitoneal injection of doxorubicin without any prior treatment (negative control) showed a significant increase $(\mathrm{p}<0.001)$ in ASAT and ALAT activities of $62.63 \%$ and $82.34 \%$ respectively. This increase ranged from 82.31 to 127.29 for ASAT activity and from 42.25 to 118.12 for ALAT activity in negative control. AESDM at 100, 200 and $300 \mathrm{mg} / \mathrm{kg}$, in the same way as vitamin-E significantly reduced the activities of these transaminases compared to the negative control $(\mathrm{p}<0.001)$. This decrease was lower than the value presented by the normal control.

Table 1 EAGDM effect on the transaminases (ASAT/ALAT) activities

\begin{tabular}{|l|l|l|}
\hline GROUPS & ASAT (UI/L) & ALAT (UI/L) \\
\hline Normal control (distilled $\left.\mathrm{H}_{2} \mathrm{O}, 10 \mathrm{~mL} / \mathrm{kg}\right)$ & $82.31 \pm 0.45$ & $42.25 \pm 0.54$ \\
\hline Negative control (distilled $\mathrm{H}_{2} \mathrm{O}, 10 \mathrm{~mL} / \mathrm{kg}$ ) & $127.29 \pm 0.35^{* * *}$ & $118.12 \pm 0.22^{* * *}$ \\
\hline Positive control $($ Vit-E, $100 \mathrm{mg} / \mathrm{kg})$ & $82.16 \pm 1.62^{\mathrm{c}}$ & $52.55 \pm 0.55^{\mathrm{c}}$ \\
\hline AESDM $100 \mathrm{mg} / \mathrm{kg}$ & $84.53 \pm 0.51^{\mathrm{c}}$ & $49.03 \pm 0.48^{\mathrm{c}}$ \\
\hline AESDM $200 \mathrm{mg} / \mathrm{kg}$ & $69.41 \pm 0.48^{\mathrm{c}}$ & $42.09 \pm 0.45^{\mathrm{c}}$ \\
\hline AESDM $300 \mathrm{mg} / \mathrm{kg}$ & $62.43 \pm 0.49^{\mathrm{c}}$ & $35.84 \pm 0.42^{\mathrm{c}}$ \\
\hline
\end{tabular}

Each value represents the mean \pm SEM, $\mathrm{n}=5$. ${ }^{* * *} \mathrm{p}<0.001$ : statistically significant compared to the normal control. cp $<0.001$ : statistically significant compared to the negative control. Vit-E = vitamin-E; AESDM = aqueous extract of seeds of Datura metel

\subsubsection{Effect of AESDM on some oxidative stress parameters}

Effect of AESDM on malondialdehyde (MDA) and glutathione (GSH) rate

Figure 1 shows that the malondialdehyde (MDA) rate, a marker of lipid peroxidation, significantly increases (P < 0.01 ) (Figure 1A) while the glutathione $(\mathrm{GSH})$ rate significantly decreases $(\mathrm{P}<0.001)$ (Figure $1 \mathrm{~B})$ in the rats' hearts injected with doxorubicin without prior pre-treatment compared to the normal group. Furthermore, the cores of the 200 and $300 \mathrm{mg} / \mathrm{kg}$ AESDM treatment rats showed a significant reduction $(\mathrm{P}<0.001)$ in MDA and a significant increase $\left(\mathrm{P}<0.001\right.$ ) in GSH compared to the negative control group (distilled $\mathrm{H}_{2} \mathrm{O}, 10 \mathrm{~mL} / \mathrm{kg}$ ).
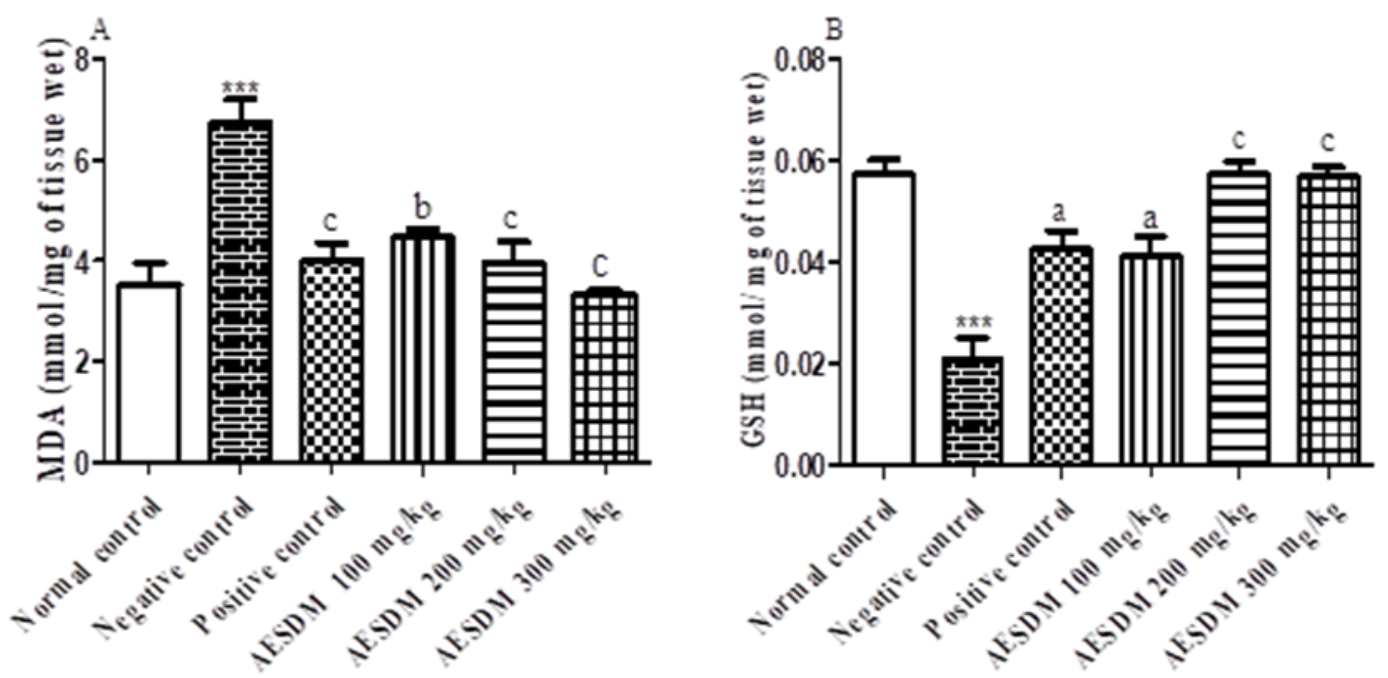
Figure 1 Effect of AESDM on MDA (A) and GSH (B) content in rat heart tissue.

Each value represents the mean 0 SEM, $\mathrm{n}=5 .^{* * *} \mathrm{p}<0.001$ : statistically significant compared to the normal control. bp $<0.01$ and $\mathrm{cp}<0.001$ : statistically significant compared to the negative control (distilled $\mathrm{H}_{2} \mathrm{O}, 10 \mathrm{~mL} / \mathrm{kg}$ ). Vit-E = vitamin-E; AESDM= Aqueous extract of seeds of Datura metel.

Effect of AESDM on superoxide dismutase (SOD) and catalase (CAT) activities

The results presented in Figure 2 illustrate the activities of superoxide dismustase (SOD) and catalase (CAT) in the rats' hearts injected with doxorubicin and various substances administered. Based on this figure, compared to the normal control, there was a significant decrease ( $\mathrm{P}<0.001$ ) of SOD (Figure 2A) and CAT (Figure 2B) activities in the rats' hearts injected with doxorubicin without prior pre-treatment (negative control). In addition, there was a significant increase $(\mathrm{P}<0.001)$ on the activity of these antioxidant enzymes in the hearts of treated rats at 200 and $300 \mathrm{mg} / \mathrm{kg}$ of AESDM as vitamin-E compared to the negative control (distilled water, $10 \mathrm{~mL} / \mathrm{kg}$ ).
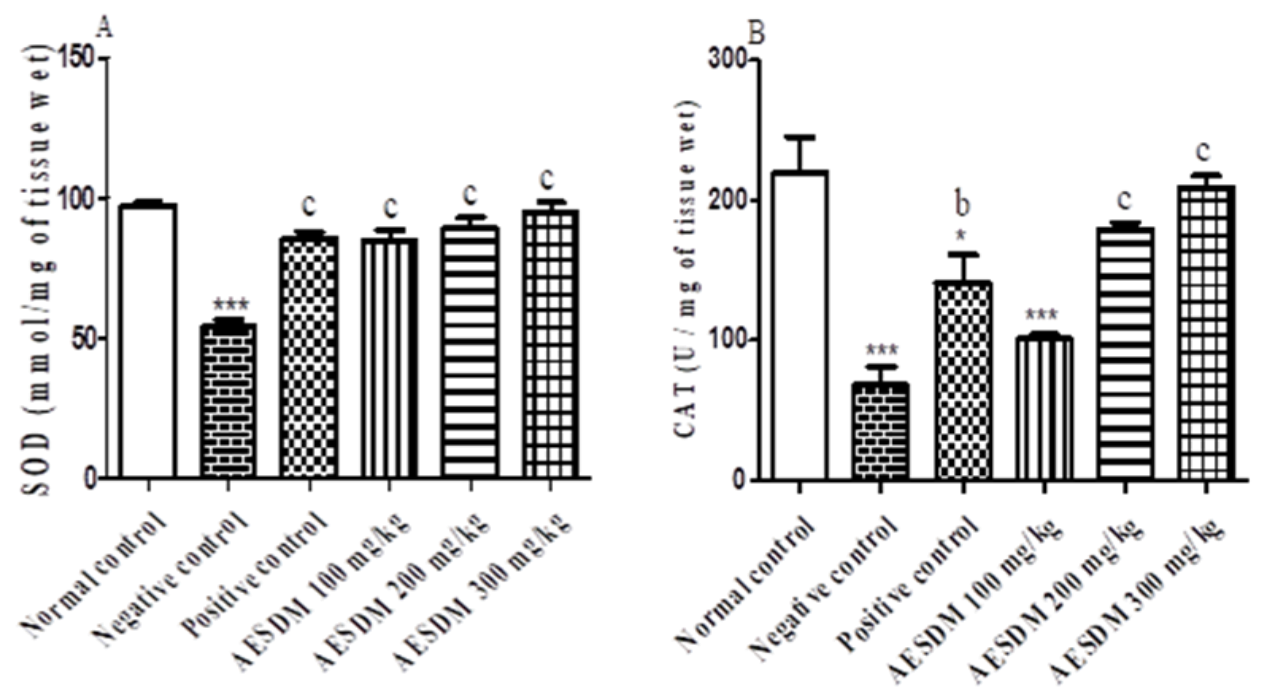

Figure 2 Effect of AESDM on superoxide dismutase (A) and catalase (B) activities of cardiac tissue.

Each value represents the mean $\pm \mathrm{SEM}, \mathrm{n}=5 .{ }^{*} \mathrm{p}<0.05$ and ${ }^{* * *} \mathrm{p}<0.001$ : statistically significant compared to the normal control. $\mathrm{bp}<0.01$ and $\mathrm{cp}<$ 0.001: statistically significant compared to the negative control (distilled $\mathrm{H}_{2} \mathrm{O}, 10 \mathrm{~mL} / \mathrm{kg}$ ). Vit-E = Vitamin-E; AESDM= Aqueous extract of seed of Datura metel

\subsubsection{Effect of EAGDM on lipid parameters}

Table 2 presents the effect of AESDM on lipid parameters (Total-cholesterol, Cholesterol-HDL, Cholesterol-LDL, Triglycerides). This table shows that serum HDL-cholesterol decreased significantly $(\mathrm{P}<0.001)$, whereas triglyceride and LDL-cholesterol increased in rats injected with doxorubicin without prior pre-treatment, compared to the normal control. Also, there was a significant increase $(\mathrm{P}<0.001)$ in serum HDL-cholesterol levels and a significant decrease in triglyceride $(\mathrm{P}<0.05)$ and LDL-cholesterol $(\mathrm{P}<0.001)$ levels in rats treated with 200 and $300 \mathrm{mg} / \mathrm{kg}$ AESDM, compared to the negative control (distilled $\mathrm{H} 20,10 \mathrm{~mL} / \mathrm{kg}$ ).

Table 2 Effect of AESDM on lipid parameters

\begin{tabular}{|l|l|l|l|l|}
\hline GROUPS & $\begin{array}{l}\text { Total-cholesterol } \\
\mathbf{( m g} / \mathbf{d L})\end{array}$ & $\begin{array}{l}\text { Cholesterol -HDL } \\
\mathbf{( m g} / \mathbf{d L})\end{array}$ & $\begin{array}{l}\text { Cholesterol- } \\
\text { LDL } \mathbf{( m g} / \mathbf{d L})\end{array}$ & $\begin{array}{l}\text { Triglycerides } \\
\mathbf{( m g} / \mathbf{d L})\end{array}$ \\
\hline Normal control & $167.71 \pm 5.60$ & $135.71 \pm 5.64$ & $18.09 \pm 1.07$ & $79.48 \pm 5.06$ \\
\hline Negative control & $175.30 \pm 2.21$ & $91.69 \pm 2.71^{* * *}$ & $37.74 \pm 1.98^{* *}$ & $179.29 \pm 3.77^{* * *}$ \\
\hline Positive control & $139.56 \pm 3.83^{* *} \mathrm{~b}$ & $112.89 \pm 3.82^{*} \mathrm{a}$ & $15.01 \pm 0.83 \mathrm{~b}$ & $58.28 \pm 4.05 \mathrm{c}$ \\
\hline AESDM 100 & $142.36 \pm 3.88^{* *} \mathrm{a}$ & $108.41 \pm 5.34^{* *}$ & $11.62 \pm 1.10 \mathrm{~b}$ & $96.71 \pm 9.03 \mathrm{a}$ \\
\hline AESDM 200 & $164.81 \pm 2.32$ & $130.12 \pm 3.14^{* *} \mathrm{~b}$ & $10.95 \pm 1.23 \mathrm{c}$ & $118.68 \pm 6.96 \mathrm{a}$ \\
\hline
\end{tabular}




\begin{abstract}
AESDM 300
$149.39 \pm 4.46$

$120.51 \pm 4.33 \mathrm{~b}$

$11.23 \pm 2.34 \mathrm{c}$

$123.23 \pm 8.98 \mathrm{a}$

Each value represents the mean \pm SEM, $n=5 .^{*} \mathrm{p}<0.05$; ${ }^{* *} \mathrm{p}<0.01$; ${ }^{* * *} \mathrm{p}<0.001$ : statistically significant compared to normal control. ap $<0.05$; bp $<$ 0.01; $\mathrm{cp}<0.001$ : statistically significant compared to the negative control (distilled $\mathrm{H}_{2} \mathrm{O}, 10 \mathrm{~mL} / \mathrm{kg}$ ). Vit-E= Vitamin-E; AESDM= Aqueous extract of seeds of Datura metel
\end{abstract}

\title{
3.1.5. Effects of AESDM on histological parameters
}

Histological sections of the cardiac tissue in the normal control showed normal morphology, narrow intracellular spaces, and absence of necrosis (Figure 3A). Cardiac muscle fibers of hearts subjected only to doxorubicin without pretreatment (Figure 3B) are irregular with loss of striations and expanded intracellular space as well as the presence of necrotic cells. When the cores are treated with vitamin E (positive control), histological sections (Figure 3C) show less damage than the negative control group. Furthermore, the pre-treatment of the hearts at different doses of AESDM probably protected the myocardium as vitamin-E. Indeed, at the dose of $200 \mathrm{mg} / \mathrm{kg}$ of AESDM, we can only notice mild edema and narrow intracellular spaces, with a normal structure similar to that of the normal control group (Figure 3E).

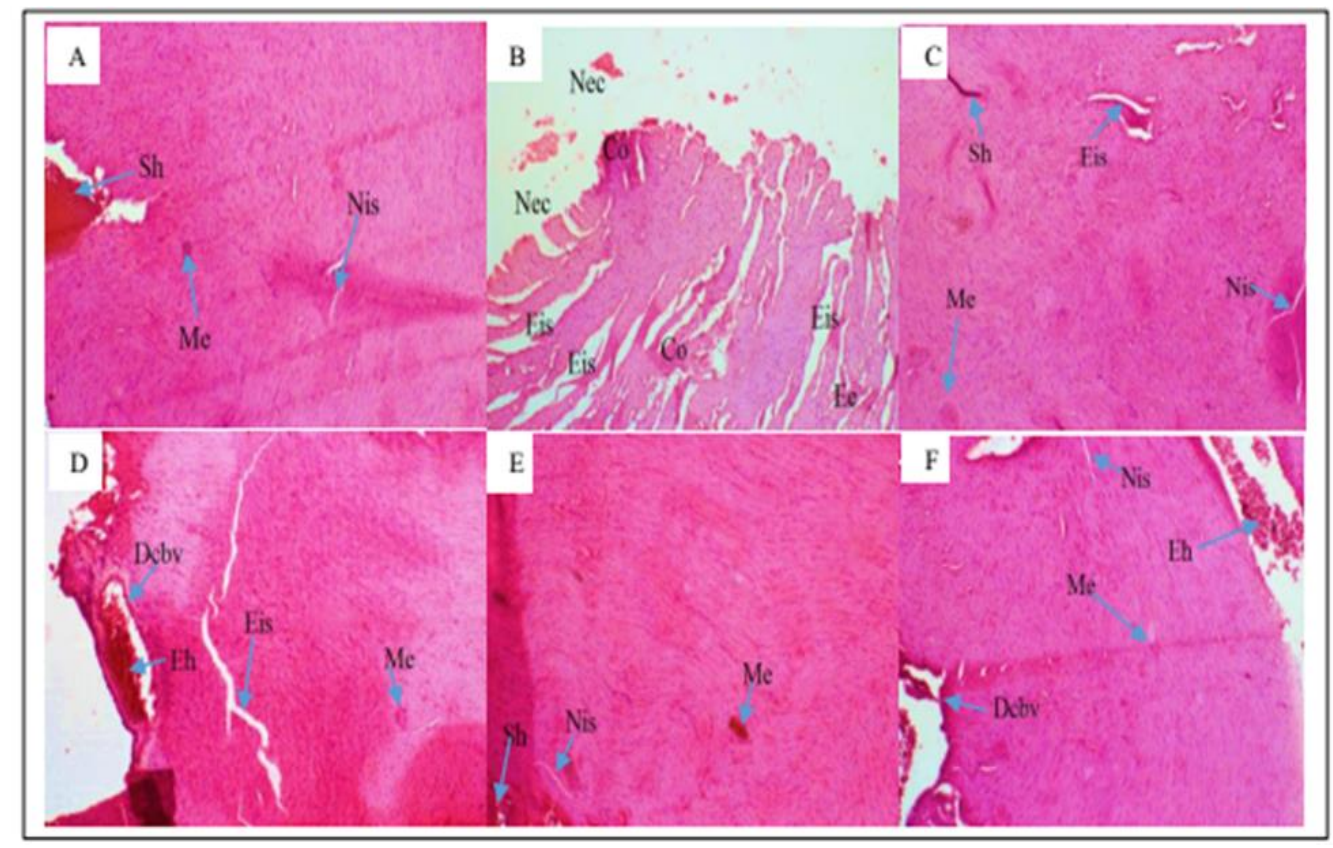

Figure 3 Micrograph of rat hearth (Hématoxylin- Eosin x 200).

$\mathrm{A}=$ Normal control; $\mathrm{B}=$ Negative control (distilled $\mathrm{H}_{2} \mathrm{O}, 10 \mathrm{~mL} / \mathrm{kg} ; \mathrm{C}=$ Positive control (Vit-E, $100 \mathrm{mg} / \mathrm{kg}$ ); D, E, F= Aqueous extract of seed of D. metel at 100, 200 and $300 \mathrm{mg} / \mathrm{kg}$ doses respectively. Sh: Slight hemorrhage; Nis: Narrow intracellular space; Me: Mild edema; Nec: Necrosis; Co: Congestion; Eis: Expanded intracellular space; Dcbv: Dilated and congested blood vessel; Eh: Expanded hemorrhage.

\subsection{Discussion}

The current paper assessed the AESDM cardioprotective effect on doxorubicin-induced cardiotoxicity (DOX). DOX is a drug used in the treatment of a variety of solid and hematological malignant tumors [36-37]. Its anti-tumor efficacy is dose-dependent, but its clinical use is limited by the congestive cardiac myopathy development and insufficiencies that it caused [38]. It has been reported by several authors that reactive oxygen species (ROS) generated during the metabolism of DOX at the origin of lipid peroxidation, play an essential role in the appearance of cardiomyopathies [39, $40,41]$. The heart is particularly sensitive to free radicals in comparison with other organs such as the liver and kidneys because of the deficiency of antioxidant defence systems in the latter [42-43]. It is commonly known that transaminases (ASAT/ALAT) are the most sensitive biomarkers, which are directly involved in the extent of cardiac damage and toxicity because they are directly released into the blood stream indicating the degree of cardiac damage [44-45]. They are generally present in all organs, used as bio-indicators and catalyze the transfer of the amino group to $\alpha$-cétoglutarate to not only form glutamate, oxaloacetate but also pyruvate, respectively [46]. Our results showed an increase in enzymatic activity of ASAT and ALAT in DOX-treated rats $(15 \mathrm{mg} / \mathrm{kg}$ ) without previous pre-treatment (negative control). The increased activity of these enzymes in the blood can be explained by the massive formation of free radicals from DOX metabolism that attack the polyunsaturated fatty acids of the cell membrane and cause lipid peroxidation leading to alterations in membrane structures and consequently weakens the functioning of the membranes by decreasing fluidity, increased permeability, decreased enzyme activity [47]. These results are in line with the findings 
of Yagmurca et al and Ioanna et al [48-49] who suggested that increased transaminase activity is a clear marker for DOX-induced cardiac toxicity. Based on the obtained results, the AESDM preventive administration at 100, 200 and 300 $\mathrm{mg} / \mathrm{kg}$ lessened the effects of DOX and normalized the activity of these enzymes. This indicates that AESDM resulted in peroxidation lipid reduction which is partly due to flavonoids present within this extract. Several previous studies have shown the cardio-protective effect of plant extracts against DOX-induced cardiac toxicity with a significant decrease in ASAT and ALAT activities [50-51]. According to several authors, oxidative stress is the main mechanism by which DOX induces cardiotoxicity [52-53]. Doxorubicin's production of free radicals within myocardial cells would damage the DNA, proteins and cell components membranes [54], with a direct consequence of the cell's evolution towards apoptosis [55]. For this reason, we explore biochemical markers of oxidative stress in cardiac tissue by assessing the levels of malondialdehyde (MDA) and reduced glutathione (GSH), as well as the antioxidant enzymes' activity (SOD and CAT). The results of this study reveal that intraperitoneal doxorubicin administration resulted in a significant increase in MDA levels, followed by a decrease in SOD and CAT activity. Our results are in line with those of $[16,56,57]$ which reported that during cardiotoxicity induced by DOX, overproduction of ROS can lead to the disruption of the antioxidant defence system in the cell. Lipid peroxidation is a process caused by free radicals, leading to the oxidative degradation of membrane polyunsaturated fatty acids and the generation of reactive aldehydes such as MDA [58], considered as the main biomarker of oxidative stress [59-60]. Furthermore, our study shows that pre-treatment with AESDM significantly reduced the concentration of MDA and led to an increase in SOD and CAT activity compared to rats in the negative group. These results suggest that AESDM was able to protect the heart from oxidative stress and DOX cytotoxic action. These results are in line with those published by several authors, which found a significant decrease in MDA heart rate, an increase in SOD and CAT activity after pre-treatment with plant extracts [43,61, 62]. On the other hand, the chemoprotector efficacy of the tested extract plant may be related to the increase in GSH concentration in AESDMtreated rats compared to the negative control. GSH, a non-enzymatic antioxidant, is the first line of defence against free radicals [63]. These results are clearly indicative of the protective power of the extract against cardiotoxicity induced by DOX as well as vitamin-E, capable of protecting cardiomyocytes against oxidative stress damage linked to its antioxidant potential [64]. The protective effect of the extract could therefore be partly explained by the richness of the plant in bioactive substances such as alkaloids, tannins and flavonoids $[22,23]$ which are antioxidant molecules known as cardiotoxicity protector [24,25]. According to several authors Alkaloids inhibit lipid peroxidation [65]. The results obtained are similar to those of Meaad et al [62] who showed that the cardioprotective effect of Ajwa date is associated with the antioxidant potential of the plant. An increase in lipid markers such as total cholesterol, LDL-cholesterol and triglycerides has been observed from the rats that received doxorubicin intraperitoneal injection without previous treatment. Conversely, AESDM treatment has resulted in a decrease in these lipoprotein markers. This decrease in serum lipoprotein concentration in this study may be explained by the fact that, D. metel is a plant very rich in bioactive compounds such as flavonoids that prevent the increase of cholesterol and triglycerides at the cellular level [66]. The most notable fact in this study is the greater effectiveness of the tested extract on lowering LDL-cholesterol and increasing HDL-cholesterol especially at the intermediate dose of $200 \mathrm{mg} / \mathrm{kg}$ which would be the most effective. Thus, like products or foods containing hypocholesterolemia and antioxidant agents, AESDM would be beneficial in preventing risk factors of cardiovascular diseases including ischemic heart disease. To support the results of serum and tissue assays of DOX cardiotoxicity biomarkers, histological study of rat cores was conducted. Based on the results obtained, doxorubicin-induced histological changes, including morphology change, vascular congestion, necrosis, large intracellular spaces [16, 67]. Conversely, in AESDM treated rats, damages were significantly reduced, suggesting protection from cellular damage by AESDM. These results stand as sufficient proof that AESDM has a beneficial effect in preventing oxidative stress and cardiotoxicity caused by doxorubicin.

\section{Conclusion}

The results obtained during this work show that AESDM prevents doxorubicin-induced toxicity. This cardioprotective effect of the tested extract plant is due to the antioxidant and hypolipidemic properties of this plant associated with a synergistic effect of certain bioactive compounds classes (alkaloids, flavonoids). This plant could be a potential source of natural pharmacological substances that can be used in the prevention of many heart diseases related to oxidative stress.

\section{Compliance with ethical standards}

\section{Acknowledgments}

The authors thank the Physiology and Pharmacognosy Laboratory, as well as the Chemistry Laboratory of the Faculty of Sciences of the University of Maroua for having made it possible to carry out this research work. 


\section{Disclosure of conflict of interest}

The authors report no conflicts of interest. The authors alone are responsible for the content and writing of this article.

\section{Statement of ethical approval}

Animal procedures were conducted with strict adherence to the NIH Guide for the care and use of Laboratory Animals (NIH Publication \#85-23 Rev. 1985).

\section{References}

[1] WHO. The top 10 causes of death. WHO Media Centre: the top 10 causes of death. 2017.

[2] Boombhi JH, Menanga A, Nkoke C, Hamadou B, Kingue S. Variabilité sinusale chez un sujet en Insuffisance cardiaque congestive à Yaoundé. Health sciences and disease. 2016; 17(1): 1-5.

[3] Agbor V, Essouma M, Ntusi N, Nyanga UF, Bigna JJR, Noubiap JJ. Heart failure in sub-Saharan Africa: A contemporaneous systematic review and meta-analysis. International Journal of Cardiology. 2018; 257: $207-215$.

[4] Damasceno A, Mayosi B, Sani M et al. The causes, treatment, and outcome of acute heart failure in 1006 Africans from 9 countries. Archive of International Medicine. 2012; 172: 1386-1394.

[5] Clovis N, Ahmadou M, Leopold N, Denis GT, Nkoualack DC, Anastase D. Heart failure in semi-urban setting in Cameroun: clinical characteristics, etiologies, treatment and outcome. Journal of Xiangya Medecine. 2019 ; 4: 6-9.

[6] Prabhu S, Mallika J, Sabitha KE, Shyamaladevi CS. Cardioprotective effect of magniferin on isoproterenol induced myocardial infraction in rats. Indian Journal of Experimental Biology. 2006; 44: 209-215.

[7] Mercadier J. Approches physiopathologiques actuelles de l'insuffisance cardiaque. Presse Médicale. 2007; 36: 979-984.

[8] McMurray J, Adamopoulos S, Anker S et al. Society of Cardiology guidelines for the diagnosis and treatment of acute and chronic heart failure. European Journal of Heart Failure. 2012; 14: 803-869.

[9] Yusuf S, Hawken S, Ounpuu TS et al. Effect of potential unmodifiable risk factors associated with myocardial infarction in 52 countries (the inter heart study): case-control study. Lancet. 2004; 364: 937-952.

[10] Takano H, Zou Y, Hasegawa H et al. Oxidative stress-induced signal transduction pathways in cardiac myocytes: involvement of ROS in heart diseases. Antioxidant and Redox Signaling. 2003; 5: 789-94.

[11] Monteil C, Mulder P, Thuillez C. oxydant et insuffisance cardiaque: une cible thérapeutique utopique? Médecine Thérapeutique de Cardiologie. 2004; 2: 78-85.

[12] Mukhopadhyay P, Rajesh M, Bátkai S, Kashiwaya Y, Haskó G, Liaudet L, Szabó C, Pacher P. Role of superoxide, nitric oxide, and peroxynitrite in doxorubicin-induced cell death in vivo and in vitro. American Journal of Physiology- Heart and Circulatory Physiology. 2009; 296(5): 1466-1483.

[13] Sterba M, Popelová O, Vávrová A, Jirkovský E, Kovaríková P, Geršl V and Simunek T. Oxidative stress, redox signaling, and metal chelation in anthracycline cardiotoxicity and pharmacological cardioprotection. Antioxidant and Redox Signaling. 2013; 18(8): 899-929.

[14] Yang F, Teves SS, Kemp CJ, Henikoff S. Doxorubicin, DNA torsion, and chromatin dynamics. Biochemistry and Biophysics Acta. 2014; 1845(1): 84-9.

[15] Asselin BL, Meenakshi D, Chen L, Vivian IF, Jeanette P, Michael JB, Robert EH, Yaddanapudi R, Saro HA, Bruce MC, Steven EL. Cardioprotection and safety of dexrazoxane in patients treated for newly diagnosed T-Cell acute lymphoblastic leukemia or advanced-stage lymphoblastic non-hodgkin lymphoma. Journal of Clinical Oncology. 2016; 34(8): 854-862.

[16] Bhupalam P, Akkiraju S, Talla S, Kanala SR, Gouruntla N, Kastury VH. Cardioprotective activity of flavonoid fraction of Gymnema sylvestre leaves on doxorubicin induced cardiac damage. Journal of Young Pharmacists. 2018; 10: 422-426.

[17] Kurek-Górecka A, Rzepecka-Stojko A, Górecki M, Stojko J, Sosada M and Swierczek- Zieba G. Structure and antioxidant activity of polyphenols derived from propolis. Molecules. 2013; 19(1): 78-101. 
[18] Georgiev V, Ananga A, Tsolova V. Recent advances and uses of grape flavonoids as nutraceuticals. Nutrients. 2014; 6(1): 391-415.

[19] Bayih T. Synergistic bioeficacy of insecticidal plants against bean bruchids (Zabrotes subfasciatus: Coleoptera) a major storage pests of common bean (Phaseolus vulgaris L.) in central rift valley of Ethiopia. MSc thesis, Department of Biology, School of Graduate Studies, Haramaya University. 2014.

[20] Kayode A, Chinedu I, Chukwuma S, Zuhairah I. Effects of ethanolic extracts of Datura metel on blood lipid profile of male albino rats. International Journal of Scientific Reports. 2014; 2: 248-252.

[21] Tsala DE, Mbida H, Nnanga N, Ngo LTE, Habtemariam S, Ze MJ. Mechanism and inotropic actions of the water extracts of the leaves and seeds of Datura metel (Solanaceae) on isolated frog's heart. American Journal of Physiology, Biochemistry and Pharmacology. 2020; 10(2): 40-47.

[22] Jakabová S, Vincze L, Farkas A et al. Determination of tropane alkaloids atropine and scopolamine by liquid chromatography-mass spectrometry in plant organs of Datura species. Journal of Chromatography. 2012; 1232: 295-301.

[23] Al- Snaifi A. Medical importance of Datura fastuosa (syn: Datura metel) and Datura stramonium. International Organization of Scientific Research Journal of Pharmacy. 2017; 7: 43-58.

[24] Du Y, Lou H. Catechin and proanthocyanidin B4 from grape seeds prevent doxorubicin-induced toxicity in cardiomyocytes. European Journal of Pharmacology. 2008; 591(3): 96-101.

[25] Vincent DT, Ibrahim YF, Espey MG, Suzuki YJ. The role of antioxidants in the erea of cardio-oncology. Cancer Chemotherapy Pharmacology. 2013; 72(6): 1157-1168.

[26] Harborne JB. Textbook of Phytochemical Methods. A Guide to Modern Techniques of Plant Analysis. 5 Edition. Chapman and Hall Ltd, London. 1998; 21-72.

[27] Saeed NM, El-Naga RN, El-Bakly WM, Abdel-Rahman HM, Salah ElDin RA, El-Demerdash E. Epigallocatechin-3gallate pretreatment attenuates doxorubicin-induced Cardiotoxicity in rats: A mechanistic study. Biochemistry and Pharmacology. 2015; 95(3): 145-55.

[28] Murray R. Aspartate aminotransferase, Alanine aminotransferase, Creatinine. Clinical Chemistry. 1984; 1112116.

[29] Wilbur KM, Bernheim F, Shapiro OW. Determination of lipid peroxidation. Arch Biochemistry and Biophysics. 1949; 24: 305-310.

[30] Misra HP, Fridovich I. The role of super oxide anion in the auto oxidation epinephrine to adrénochrome and a simple assay for superoxide dismutase. Journal of Biological Chemistry. 1972; 247: 3170-3175.

[31] Sinha AK. Colorimetric assay of catalase. Anal of Biochemistry. 1972; 47: 389-394.

[32] Ellman GL. Tissue sulfhydryl group. Archives of Biochemistry and Biophysics. 1959; 82: 70-77.

[33] Parekh AC, Jung DH. Cholesterol determination with ferric acetate-uranium acetate and sulfuric acid-ferrous sulfate reagents. Analytical Chemistry. 1970; 42: 1423-1427.

[34] Rice EW. Standard method of clinical chemistry. New York: Academic Press. 1970.

[35] Burstein M, Scholnick HR. Lipoprotein-polyanionmetal interactions. Advances in Lipid Research. 1973; 11: 67108.

[36] Judson I, Verweij J, Gelderblom H, Hartmann JT, Schöffski P, Blay JY. Doxorubicin alone versus intensified doxorubicin plus ifosfamide for first-line treatment of advanced or metastatic soft-tissue sarcoma: a randomised controlled phase 3 trial. Lancet Oncology. 2014; 15(4): 415-423.

[37] Mustafa HN, El-Awdan SA, Hegazy GA, Abdel JGA. Prophylactic role of coenzyme Q10 and Cynara scolymus L on doxorubicin-induced toxicity in rats: Biochemical and immunohistochemical study. Indian Journal of Pharmacology. 2005; 47(6): 649-56.

[38] Chatterjee K, Zhang J, Hombo N and Karliner J. Doxorubicin Cardiomyopathy. Cardiology. 2010; 115(2): $155-162$.

[39] Delemasure S, Vergely C, Zeller M, Cottin Y, Rochette L. Prévention de la cardiotoxicité des anthracyclines : approche fondamentale des mécanismes mis en jeu ; relations avec les données cliniques. Annales de Cardiologie et d'Angéiologie. 2006; 55: 104-112. 
[40] Sterba M, Popelová O, Vávrová A, Jirkovský E, Kovaríková P, Geršl V and Simunek T. Oxidative stress, redox signaling, and metal chelation in anthracycline cardiotoxicity and pharmacological cardioprotection. Antioxidant and Redox Signaling. 2013; 18(8): 899-929.

[41] Colombo A, Cipolla C, Beggiato M, Cardinale D. Cardiac toxicity of anticancer agents. Current Cardiology Reports. 2013; 15: 357-362.

[42] Octavia Y, Tocchetti C, Gabrielson K et al. Doxorubicin-induced cardiomyopathy: from molecular mechanisms to therapeutic strategies. Journal of Molecular and Cellular Cardiology. 2012; 52: 1213-1225.

[43] Akkiraju SYP, Venkatesh P, Ranjith KK, Suma V, Rojapathi NM. Cardioprotective Effect of Clove Oil in Isoprenaline Induced Myocardial Infarction on Male Wistar Rats: Ethnopharmacology. 2014; 2: 1-3.

[44] Kamoun P, Lavoinne A, De Verneuil. Biochimie et biologie moléculaire. EDS Flammarion Médecine-sciences. 2003; 114-115.

[45] Walker DB. Serum Chemical Biomarkers of Cardiac injury for Nonclinical Safety Testing. Toxicologic Pathology. 2006; 34: 94-104.

[46] Mazevet M, Moulin M, Llach-Martinez A et al. Complications of chemotherapy, a basic science update. Presse Medicale. 2013; 42: 352-61.

[47] Barnabé N, Zastre JA, Venkataram S, Hasinoff BB. Deferiprone protects against doxorubicin-induced myocyte cytotoxicity. Free radical biology and Medicine. 2002; 33 (2): 266-275.

[48] Yagmurca M, Fadillioglu E, Erdogan H, Ucar M, Sogut S, Irmak MK. Erdosteine prevents doxorubicin-induced cardiotoxicity in rats. Pharmacology Research. 2003; 48(4): 377-382.

[49] Ioanna A, Fragiska S, Efstathios KI, Maria P, Constantinos S, Nektarios A, Paraskevi S, Vassilis G, Efstathios P, Dimitrios TK. Acute doxorubicin cardiotoxicity is successfully treated with the phytochemical oleuropein through suppression of oxidative and nitrosative stress. Journal of Molecular and Cellular Cardiology. 2007; 42: 549-558.

[50] El-Boghdady NA. Antioxidant and antiapoptotic effects of proanthocyanidin and Ginkgo biloba extract against doxorubicin-induced cardiac injury in rats. Cell Biochemistry Function. 2013; 31: 344-351.

[51] Kara AW, Ihoual S, Abidli N. The Combination Therapy of Medicinal Plant Globularia alypum, with Adriamycin Limits Free Radical Mediated Cardiac Injury in Rats. International Journal of Pharmaceutical Sciences Review and Research. 2016; 36(1): 1-8.

[52] Hassan M, El-Beshbishy H, Aly H et al. Modulatory effects of meloxicam on cardiotoxicity and antitumor activity of doxorubicin in mice. Cancer Chemotherapy and Pharmacology. 2014; 74: 559-569.

[53] Zhang XJ, Cao XQ, Zhang CS, Zhao Z. 17ß-estradiol protects against doxorubicin-induced cardiotoxicity in male Sprague-Dawley rats by regulating NADPH oxidase and apoptosis genes. Molecular Medicine Reports 2017; 15(5): 2695-2702.

[54] Iarussi D, Indolfi F, Casale P et al. Recent advances in the prevention of anthracycline cardiotoxicity in childhood. Current Medicinal Chemistry. 2001; 8: 1649-1660.

[55] Xu X, Persson HL, Richardson DR. Molecular pharmacology of the interaction of anthracyclines with iron. Molecular Pharmacology. 2005; 68(2): 261-271.

[56] Bandari U, Shweta S, Madhusudhana K, Bidya DS, Challa VS, Rajeswara RP, Naidu VGM, Ramakrishna S. Ethanolic extract of Boswellia ovalifoliolata bark and leaf attenuates doxorubicin-induced cardiotoxicity in mice. Environmental toxicology and pharmacology. 2013; 36: 840-849.

[57] Abdalla A. Ameliorative influence of dietary dates on doxorubicin-induced cardiac toxicity. Intensive Care Medicine,. 2016; 7: 343-353.

[58] Mazunder UK, Gupta M, Rajeshwar Y. Antihyperglycemic effect and antioxidant potential of Phyllanthus niruri (Euphorbiaceae) in streptozotocin induced diabetic rats. European Bulletin of Drug Research. 2005; $13(1): 13$ 23.

[59] Favier A. conceptuel et expérimental dans la compréhension des mécanismes des maladies et potentiel thérapeutique. L'actualité Chimique. 2003; 108 - 115.

[60] Milane H. La quercétine et ses dérivés: molécules à caractère prooxydant ou capteurs de radicaux libres; études et applications thérapeutiques. Thèse de doctorat de l'université de Louis Pasteur. 2004; 13-36. 
[61] Abba P, Souleymane M, Lydie B, Dodehe Y, Tanoh H, Jean D. Cardioprotective and anti-inflammatory activities of polyphenols enriched extract of Hibiscus sabdariffa petal extracts in wistar rats. Journal of Pharmacognosy and Phytochemistry. 2015; 4(1): 57-63.

[62] Meaad FS, Fawzia AA, Othman ASB, Mazin AZ, Lobna S, Ibrahim AH, Aymn TA, Mohamed KA. Cardioprotective effect of Ajwa date aqueous extract on doxorubicine-induiced toxicity in rats. Biomedical and pharmacology Journal. 2018; 11(3): 1521-1536.

[63] Sathishsekar D, Subramanian S. Antioxidant properties of Momordica charantia (Bitter gourd) seeds on Streptozotocin induced diabetic rats. Asia Pacific Journal of Clinical Nutrition. 2005; 14 (2): 153- 158.

[64] Velavan S, Selvarani S, Adhithan A. Cardioprotective effect of Trichopus zeylanicus against myocardial ischemia induced by isoproterenol in rats. Bangladesh Journal of Pharmacology. 2009; 4: 88-91.

[65] Gan J, Feng Y, He Z, Li X, Zhang H. Correlations between Antioxidant Activity and Alkaloids and Phenols of Maca (Lepidium meyenii), Journal of Food Quality. 2017; 1-10.

[66] Anila L, Vijayalakshmi NR. Flavonoids from Emblica officinalis and Mangifera indica-effectiveness for dyslipidemia. Journal of Ethnopharmacology. 2002; 79(1): 81-87.

[67] Abdelbaky N, Ali A, Raeesa M. Cardioprotective effect of simvastatin on doxorubicin induced oxidative cardiotoxicity in rats. Australian Journal of Basic and Applied Sciences. 2010; (1): 29-38. 